\title{
Scottish Deerhound
}

National Cancer Institute

\section{Source}

National Cancer Institute. Scottish Deerhound. NCI Thesaurus. Code C53919.

The Scottish Deerhound is a tall and slim sight hound with a saggy, long coat, beard, mustache and mane. The harsh, wiry coat comes in various shades of gray (blue-gray is preferred), fawn, or brindle, with dark ears and a tapering dark muzzle. It may have some white on the chest, feet and tail. The soft ears lie back against the head unless the dog is excited, in which case, they become half-perked. Height: 28-32 inches (71-81 cm.)

Weight: 75-110 pounds (34-50 kg.) 